7. Mai P-T, Le D-T, Nguyen T-T, et al. Novel GDAP1 Mutation in a Vietnamese Family with Charcot-Marie-Tooth Disease. BioMed Research International. 2019;6. doi:10.1155/2019/7132494
8. Chen S-T, Wu S, Su $C$, et al. Association of ABCG2 rs2231142-A allele and serum uric acid levels in male and obese individuals in a Han Taiwanese population. J Formos Med Assoc. 2017; 116(1):18-23. doi:10.1016/j.jfma.2015.12.002

\title{
KHẢO SÁT MộT SỐ YẾU TỐ LIÊN QUAN ĐẾN TÍNH CHẤT TÂN SẢN HOĂC ÁC TÍNH CỦA POLYP TÚI MÂTT
}

\section{TÓM TẮT}

Muc tiêu: Khảo sát mô̂t số yếu tố liên quan đến tính chất tân sản hoặc ác tính của polyp túi mật. Phương pháp: Nghiên cứu mô tả cắt ngangtrên 95 bệnh nhân được phát hiện có polyp túi mật trên bệnh phẩm cắt túi mât tai bệnh viên Đai hoc Y Hà Nồi tù 01/2019 đến 10/2019. Kết quả: Tỉ lệ tân sản và tỉ lệ ung thư ở những trường hợp có trên 01 polyp và polyp kích thước dưới $10 \mathrm{~mm}$ thấp hơn các tỉ lệ tương ứng ở những trường hợp chỉ có 01 polyp và polyp kích thước từ $10 \mathrm{~mm}$ trở lên; tỉ lệ polyp ung thư ở những người từ 50 tuổi trở xuống thấp hơn tỉ lệ tương ứng ở những người trên 50 tuổi. Những sự khác biệt trên đều có ý nghĩa thống kê với $p<0,05$. Kết luận: Trên 50 tuổi, polyp kích thước từ $10 \mathrm{~mm}$ trở lên, chỉ có 01 polyp là các yếu tố có liên quan đến tính chất tân sản hoặc ác tính của polyp túi mâtt.

Tư khoá: Polyp túi mật, tân sản, ác tính

\section{SUMMARY}

INVESTIGATE SEVERAL FACTORS

\section{ASSOCIATED WITHNEOPLASTIC OR}

MALIGNANTGALLBLADDER POLYPS

Purpose: Investigate several factors associated with neoplastic or malignant gallbladder polyps. Methods: A descriptive cross-sectional study was conducted on 95 patients with gallbladder polyps on cholecystectomy specimens at Hanoi Medical University Hospital from January 2019 to October 2019. Results: The rates of neoplastic polyps and cancerous polyps in cases with more than one polyp and polyps less than $10 \mathrm{~mm}$ in size were significantly lower than the figures for cases with only 1 polyp and polyps of $10 \mathrm{~mm}$ or more. The rate of cancerous polyps of those aged 50 and younger was lower than that of those over 50 years old. These differences were statistically significant with $p<0.05$. Conclusions: Over the age of 50 , polyps of $10 \mathrm{~mm}$ or more in size, only 01 polyp are factors associated with

\section{${ }^{1}$ Trường Đại học Y Hà Nội}

2Bênh viên Đai hoo Y Hà Nôi

Chịu trách nhiệm chính: Nguyễn Thị Quỳnh

Email: quynh95hmu@gmail.com

Ngày nhận bài: 15.9.2021

Ngày phản biên khoa họ: 12.11.2021

Ngày duyệt bài: 23.11.2021
Đào Thị Luận ${ }^{1,2}$, Đặng Đức Thịnh ${ }^{1,2}$, Nguyễn Thị Quỳnh ${ }^{1}$, Trần Ngọc Minh ${ }^{1,2}$ neoplastic or malignant gallbladder polyps.

Keywords: Gallbladder polyps, neoplastic, malignant

\section{I. ĐĂT VẤN ĐỀ}

Polyp túi mật là tổn thương dạng lồi do sự phát triển, tăng sinh không bình thường, nhô lên từ bề mặt niêm mạc túi mật. Tỉ lệ gặp polyp túi mật được báo cáo trong y văn thay đổi từ 1,3\% đển $6,9 \%$ cho cả hai giới trên tất cả các trường hợp cắt túi mật. Bệnh gặp ở cả 2 giới mặc dù không có sự ưu thế rõ rệt ở giới nào và ở nhiều lứa tuổi, tuy nhiên rất hiếm ở trẻ em. ${ }^{1}$ Về bản chất mô bệnh học, polyp túi mật có thể phân làm hai loại chính là tổn thương tân sản thực sự và tổn thương không phải tân sản. Tại Bệnh viện Đại học Y Hà Nội, thống kê mỗi tháng có khoảng 40-60 ca phẫu thuật cắt polyp túi mật, tuy nhiên thực tế chưa có nghiên cứu nào tại đây về đặc điểm mô bệnh học cũng như các yếu tố nguy cơ ác tính hóa của polyp túi mật để giúp định hướng điều trị và tiên lượng bệnh một cách đầy đủ. Vì vậy, chúng tôi tiến hành nghiên cứu nhằm mục tiêu: Khảo sát một số yếu tố liên quan đến tính chất tân sản hoặc ác tính của polyp túi mật.

\section{II. ĐỐI TƯỢNG VÀ PHƯƠNG PHÁP NGHIÊN CỨU}

Đối tượng nghiên cứu. Gồm 95 người bệnh được phát hiện có polyp túi mật trên bệnh phẩm cắt túi mật tại bệnh viện Đại học Y Hà Nội từ 01/2019 đến 10/2019.

\section{Tiêu chuẩn lựa chọn}

- Người bệnh được chẩn đoán có polyp túi mật trên kết quả giải phẫu bệnh bệnh phẩm phẫu thuật.

- Có đủ tiêu bản mô bệnh học và khối nến.

- Có hồ sơ bệnh án đủ các biến số cần thiết cho nghiên cứu.

Tiêu chuẩn loại trừ. Người bệnh không thoả mãn một trong các tiêu chuẩn lựa chọn trên.

Thời gian và địa điểm nghiên cứu

- Thời gian: từ 07/2020 đến 07/2021.

- Địa điểm: Khoa Giải phẫu bệnh - Bệnh viện 
Đại học Y Hà Nội.

Phương pháp nghiên cứu

Thiết kế nghiên cứu: Nghiên cứu mô tả cắt ngang.

Chọn mẫu nghiên cứu: Chọn mẫu có chủ đích, bao gồm 95 người bệnh thỏa mãn tiêu chuẩn lựa chọn.

Các biến số nghiên cứu:

- Đặc điểm của đối tượng nghiên cứu:

+ Giới: nam, nữ

+ Tuổi: $\leq 50,>50$

- Đặc điểm polyp túi mật:

+ Các típ mô bệnh học

+ Tính chất tân sản/u hoặc ung thư

+ Số lượng: 01 polyp, > 01 polyp

+ Kích thước: $<10 \mathrm{~mm}, \geq 10 \mathrm{~mm}$

+ Sỏi: không/có

- Mối liên quan giữa tính chất tân sản/u hoặc ác tính của polyp túi mật với các yếu tố giới tính, tuổi, số lượng, kích thước polyp, tình trạng sỏi.
Quy trình tiến hành nghiên cứu:

- Xây dựng phiếu thu thập thông tin.

- Thu thập thông tin hành chính của người bệnh theo hồ sơ bệnh án.

- Thu thập thông tin đại thể, vi thể của polyp và túi mật theo các chỉ số/biến số nghiên cứu.

- Thu thâap tiêu bản HE và khối nến kèm theo.

- Phân tích và xử lí số liệu.

Phân tích và xử lí số liệu: Phân tích và xử lý số liệu sử dụng phần mềm Excel 2013 và SPSS 25.0.

\section{Đạo đức nghiên cứu:}

- Tất cả biến số, chỉ số đều được thu thập, tính toán trung thực và khoa học.

- Nghiên cứu chỉ nhằm mục đích nâng cao chất lượng chẩn đoán, điều trị, tiên lượng bệnh, giúp chăm sóc, nâng cao sức khỏe, chất lượng cuộc sống người bệnh.

\section{KẾT QUẢ NGHIÊN CỨU}

Bảng 1. Phân bố bệnh nhân theo tính chât tân sản/u của polyp túi mật

\begin{tabular}{|c|c|c|c|c|}
\hline \multicolumn{2}{|c|}{ Típ mô bệnh học } & Số lương (n) & Tống (n) & Tỉ lê (\%) \\
\hline \multirow{2}{*}{$\begin{array}{l}\text { Polyp không có tính } \\
\text { chất tân sản }\end{array}$} & Polyp cholesterol & 77 & \multirow{2}{*}{83} & \multirow{2}{*}{87,4} \\
\hline & Polyp viêm & 6 & & \\
\hline \multirow{5}{*}{$\begin{array}{l}\text { Polyp có tính chất } \\
\text { tân sản/u }\end{array}$} & U tuyếnloạn sản độ thấp & 4 & \multirow{5}{*}{12} & \multirow{5}{*}{12,6} \\
\hline & U tuyến loạn sản độ cao & 2 & & \\
\hline & Tân sản nhú độ thấp & 2 & & \\
\hline & Tân sản nhú độ cao & 1 & & \\
\hline & Ung thư biếu mô & 3 & & \\
\hline \multicolumn{2}{|c|}{ Tốna } & 95 & 95 & 100,0 \\
\hline
\end{tabular}

Nhận xét: Polyp không có tính chất tân sản chiếm đa số trong nghiên cứu với 83 trường hợp (chiếm 87,4\%), trong đó, chủ yếu là polyp cholesterol với 77 trường hợp. 12 trường hợp polyp có tính chất tân sản/u được ghi nhận (bao gồm u tuyến, tân sản nhú và ung thư biểu mô), chiếm 12,6\%.

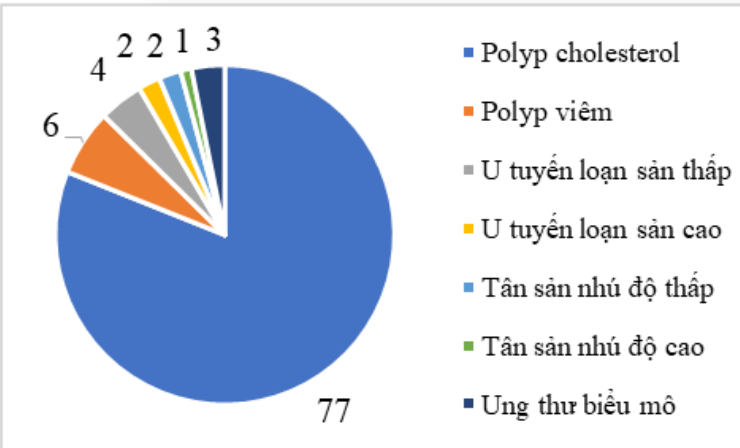

mô bênh họ của polyp túi mật

Nhân xét: Trong nghiên cứu này, chúng tôi nhận thấy polyp cholesterol hay gặp nhất với 77 trường hợp, chiếm $81,1 \%$. Tân sản nhú túi mật (gồm 02 trường hợp tân sản độ thấp và 01 trường hợp tân sản độ cao) và ung thư biểu mô túi mật ít gặp nhất, đều có số trường hợp mắc là 3 người, chiếm 3,2\%. U tuyến túi mật (gồm 04 trường hợp loạn sản độ thấp và 02 trường hợp loạn sản độ cao) và polyp viêm đều gặp 6 trường hợp trong nghiên cứu.

\section{Biểu đồ 1. Phân bố bệnh nhân theo các típ}

Bảng 2. Phân bồ bệnh nhân theo tính chất ác tính của polyp túi mật

\begin{tabular}{|c|c|c|c|c|}
\hline \multicolumn{2}{|c|}{ Típ mồ bệnh học } & Số lượng (n) & Tống (n) & Tỉ lệ (\%) \\
\hline \multirow{3}{*}{$\begin{array}{c}\text { Polyp không } \\
\text { ung thư }\end{array}$} & Polyp cholesterol & 77 & \multirow{3}{*}{8} & \multirow{2}{*}{93,7} \\
\cline { 2 - 3 } & Polyp viêm & 6 & \multirow{2}{*}{9} \\
\cline { 2 - 3 } & U tuyến loạn sản độ thấp & 4 & \\
\cline { 2 - 3 } & Tân sản nhú độ thấp & 2 & \\
\hline
\end{tabular}


VIETNAM MEDICAL JOURNAL N²0 - DECEMBER - 2021

\begin{tabular}{|l|c|c|c|c|}
\hline \multirow{2}{*}{ Polyp ung thư } & U tuyến loạn sản độ cao & 2 & \multirow{2}{*}{6} & \multirow{2}{*}{6,3} \\
\cline { 2 - 3 } & Tân sản nhú độ cao & 1 & & \\
\cline { 2 - 3 } & Ung thư biếu mô & 3 & 95 & 100,0 \\
\hline
\end{tabular}

Nhận xét: Polyp không ung thư (bao gồm polyp cholesterol, polyp viêm, u tuyến loạn sản độ thấp và tân sản nhú độ thấp) chiếm đa số với 89 trường hợp được ghi nhận trong nghiên cứu, chiếm $93,7 \%$. Polyp ung thư chiếm tỉ lệ thấp hơn đáng kể với 6,3\% (6 trường hợp), bao gồm u tuyến loạn sản độ cao, tân sản nhú độ cao và ung thư biểu mô.

Bảng 3. Một só yếu tố liên quan đến tính chât tân sản hoăc ác tính của polyp túi mật

\begin{tabular}{|c|c|c|c|c|c|c|}
\hline \multicolumn{2}{|c|}{ Một số yếu tố } & $\begin{array}{c}\text { Số beênh } \\
\text { nhân n (\%) }\end{array}$ & $\begin{array}{l}\text { Polyp có tính châtt } \\
\text { tân sản } n(\%)\end{array}$ & $\mathbf{p}$ & $\begin{array}{l}\text { Polyp ung } \\
\text { thư n (\%) }\end{array}$ & p \\
\hline \multirow{2}{*}{ Giới } & Nam & $30(31,6)$ & $3(10,0)$ & \multirow{2}{*}{0,747} & $1(3,3)$ & \multirow{2}{*}{0,661} \\
\hline & Nữ & $65(68,4)$ & $9(13,8)$ & & $5(7,7)$ & \\
\hline \multirow[b]{2}{*}{ Tuổi } & $\leq 50$ & $58(61,1)$ & $6(10,3)$ & \multirow{2}{*}{0,529} & $1(1,7)$ & \multirow[b]{2}{*}{0,032} \\
\hline & $>50$ & $37(38,9)$ & $6(16,2)$ & & $5(13,5)$ & \\
\hline Kích thước & $<10 \mathrm{~mm}$ & $88(92,6)$ & $5(5,7)$ & \multirow[b]{2}{*}{0,000} & $0(0,0)$ & \multirow[b]{2}{*}{0,000} \\
\hline polyp & $\geq 10 \mathrm{~mm}$ & $7(7,4)$ & $7(100,0)$ & & $6(85,7)$ & \\
\hline Số lượng & 01 polyp & $24(25,3)$ & $7(29,2)$ & \multirow{2}{*}{0,01} & $4(16,7)$ & \multirow[b]{2}{*}{0,034} \\
\hline polyp & $>01$ polyp & $71(74,7)$ & $5(7,0)$ & & $2(2,8)$ & \\
\hline \multirow{2}{*}{ Sỏi } & Khô̂ng & $57(60,0)$ & $9(15,8)$ & \multirow[b]{2}{*}{0,351} & $4(7,0)$ & \multirow[b]{2}{*}{1,000} \\
\hline & Có & $38(40,0)$ & $3(7,9)$ & & $2(5,3)$ & \\
\hline
\end{tabular}

Nhân xét: - Tỉ lệ u của polyp túi mật kích thước dưới $10 \mathrm{~mm}(5,7 \%)$ thấp hơn so với tỉ lệ tương ứng của polyp túi mật kích thước từ $10 \mathrm{~mm}$ trở lên $(100,0 \%)$. Tỉ lệ gặp tân sản của những trường hợp có trên 01 polyp $(7,0 \%)$ thấp hơn tỉ lệ tương ứng của những trường hợp chỉ có 01 polyp $(29,2 \%)$.

- Tî lệ polyp ung thư của những người từ 50 tuổi trở xuống $(1,7 \%)$ thấp hơn tỉ lệ tương ứng của những người trên 50 tuổi $(13,5 \%)$. Tỉ lệ ung thư của polyp có kích thước dưới $10 \mathrm{~mm}(0,0 \%)$ thấp hơn tỉ lệ tương ứng của polyp có kích thước từ $10 \mathrm{~mm}$ trở lên $(85,7 \%)$. Tî lệ ung thư của những trường hợp có 01 polyp $(16,7 \%)$ cao hơn tỉ lệ tương ứng của những trường hợp có trên 01 polyp (2,8\%).

- Những sự khác biệt trên có ý nghĩa thống kê với $p<0,05$.

\section{BÀN LUẬN}

Trong nghiên cứu của chúng tôi, polyp cholesterol là loại polyp túi mật hay gặp nhất với 77 trường hợp, chiếm 81,1\% (Biểu đồ 1). Kết quả này tương đồng với các kết quả nghiên cứu được ghi nhận trong y văn từ trước tới giờ. Polyp cholesterol có thể được coi là biểu hiện dạng polyp của bệnh tích tụ cholesterol (Cholesterolosis) trong thành túi mật với tần suất gặp ở người từ 9 đến $26 \%$ theo các nghiên cứu ngoại khoa. ${ }^{2}$ Li Y và cs (2018) nghiên cứu trên 2290 trường hợp cắt túi mật do chẩn đoán polyp túi mật trên siêu âm cho con số tần suất của bệnh tích tụ cholesterol là 20,2\%. Polyp viêm là loại ít găp nhất trong các polyp túi mât không có tính chất u, chiếm khoảng $10 \%$ các polyp không có u và thường có kích thước dưới $10 \mathrm{~mm} .^{3}$ Nghiên cứu của chúng tôi gồm 06 trường hợp polyp viêm, chiếm $6,3 \%$ với kích thước đều dưới 10 mm (Biểu đồ 1).

Nghiên cứu của chúng tôi bao gồm 12 trường hợp polyp có tính chất tân sản/u, chiếm tỉ lệ $12,6 \%$; trong đó, 04 trường hợp u tuyến loạn sản độ thấp, 02 trường hợp u tuyến loạn sản độ cao, 02 trường hợp tân sản nhú độ thấp, 01 trường hợp tân sản nhú độ cao và 03 trường hợp ung thư biểu mô tuyến (Bảng 1).Trong các trường hợp này, các tổn thương u tuyến loạn sản độ cao, tân sản nhú độ cao đều có thể được coi là các tổn thương ung thư tại chố của niêm mạc túi mật theo Tổ chức $Y$ tế thế giới đến thời điểm hiện tại (Bảng 2).

Taskin và cS (2020) nghiên cứu trên 643 bệnh nhân có polyp túi mật trên bệnh phẩm phẫu tích túi mật, nhận thấy 223 bệnh nhân có polyp với tính chất tân sản, chiếm tỉ lệ $34,6 \%$, cao hơn tỉ lệ tương ứng trong nghiên cứu chúng tôi; trong đó, chiếm đa số là tân sản nội nang với 164 trường hợp, 33 trường hợp có biến đổi loạn sản và 26 trường hợp là ung thư biểu mô xâm nhập dạng polyp. Cũng theo nghiên cứu này, 420 trường hợp polyp không có tính chất tân sản được ghi nhận, chiếm tỉ lệ 65,4\%; trong đó, polyp xơ tuyến chiếm chủ yếu với 196 trường hợp, tiếp theo là polyp cholesterol (166 trường hợp), dị sản tuyến hang vị dạng polyp (41 
trường hợp) và chiếm tỉ lệ thấp nhất là polyp viêm với 17 trường hợp được ghi nhận. ${ }^{4}$ Theo Roa I. và cs (2004) trong một nghiên cứu trên 21.412 bệnh nhân được phẫu thuật cắt túi mật, 85\% polyp không có tính chất tân sản, trong đó, polyp tuyến hang vị, polyp cholesterol, polyp tăng sản và polyp viêm chiếm tỉ lệ theo thứ tự giảm dần, lần lượt là $32 \%, 29 \%, 22 \%$ và $2 \% .^{5}$ Các kết quả nghiền cứu này khá tương đồng với kết quả nghiên cứu của chúng tôi, đều thống nhất rằng, polyp không có tính chất tân sản chiếm tỉ lệ cao hơn đáng kể so với polyp có tính chất tân sản/u.

Nghiên cứu quan sát thấy tỉ lệ polyp có tính chất tân sản/u của nam giới $(10,0 \%)$ thấp hơn của nữ giới $(13,8 \%)$; tỉ lệ polyp ung thư của nam giới $(3,3 \%)$ thấp hơn của nữ giới $(7,7 \%)$ (Bảng 3), tuy nhiên, những sự khác biệt này không có ý nghĩa thống kê với $\dot{p}>0,05$. Lee $S R$ và $C S$ (2019) nghiên cứu trên 516 người bệnh cho kết quả tỉ lệ polyp ung thư của nam và nữ là bằng nhau, sự khác biệt không có ý nghĩa thống kê với $p>0,05 .^{6}$

Trong nghiên cứu của chúng tôi, tỉ lệ polyp có tính chất tân sản/u và tỉ lệ polyp ung thư đều tăng cao hơn hẳn ở những người trên 50 tuổi so với những người từ 50 tuổi trở xuống, trong đó có mối liên quan có ý nghĩa thống kê giữa tuổi và polyp ung thư với $p<0,05$ (Bảng 3 ). Theo $y$ văn hiện tại, độ tuổi được coi là một trong các yếu tố nguy cơ của polyp túi mật ung thư và đã được đưa vào trong khuyến cáo của các tổ chức y tể châu Âu kể từ năm 2017. Tương tự như nhiêu loại ung thư ở cơ quan khác, nguy cơ polyp túi mật là một tổn thương ung thư thực sự tăng theo tuổi của người bệnh. Nhiêu ngưỡng tuổi đã được đưa ra, tuy nhiên ngưỡng chủ yếu được nhiều nghiên cứu khuyên để phân loại nguy cơ ác tính polyp túi mật là 50 tuổi.

Về mối liên quan với số lượng polyp, nghiên cứu của chúng tôi cho thây tî̀ lệ polyp có tính chất tân sản/u ở những trường hợp đợn polyp $(29,2 \%)$ cao hơn đa polyp $(7,0 \%)$; tỉ lệ ung thư của những trường hợp đơn polyp $(16,7 \%)$ cao hơn đa polyp (2,8\%). Những sự khác biệt này đều có ý nghĩa thống kê với $\mathrm{p}<0,05$ (Bảng3). Theo nhiêu nghiên cứu, các polyp tân sản thường có xu hướng đơn độc, trong khi polyp cholesterol thường có nhiều. Polyp ác tính cũng thường thây ở các trường hợp polyp đơn độc hơn, mặc dù theo nghiên cứu của Bhatt và cs (2016) thì nguy cơ ác tính chỉ tăng gấp 2,05 lần. ${ }^{7}$

Theo kết quả nghiên cứu, 100\% (7/7 trường hợp) polyp túi mật kích thước từ $10 \mathrm{~mm}$ trở lên có tính chất mô bệnh học của u hay nói cách khác polyp có tính chất mô bệnh học của một tổn thương tân sản thực sự. Trong đó, 85,7\% (6/7 trường hợp) các polyp này là một tổn thương ung thư thật sự và 01 trường hợp polyp túi mật còn lại có bản chất mô bệnh học là u tuyến loạn sản độ thấp. Ngược lại, những trường hợp polyp có kích thước dưới $10 \mathrm{~mm}$ thì tỉ lệ polyp là một tổn thương tân sản hoặc ung thư thấp hơn hẳn, lần lượt là $5,7 \%$ và $0,0 \%$. Mối liên quan giữa bản chất mô bệnh học là một tổn thương tân sản hoặc nặng hơn là một tổn thương ung thư có liên quan có ý nghĩa thống kê với kích thước polyp, với $p<0,05$ và $p<0,001$ tương ứng (Bảng 3).Trong một nghiên cứu hồi cứu trên toàn quốc tại Hà Lan được công bố trong năm 2018, các tác giả đã tìm thây 2085 trường hợp có polyp túi mật $(0,9 \%)$ trong tổng số 220.612 người được cắt túi mật. Trong những trường hợp này $56 \%$ polyp là tân sản thực sự $(40,1 \%$ là tiền ung thư; $59,9 \%$ là ung thư'). Kích thước của các polyp tân sản có sự khác biệt có ý nghĩa thống kê với các polyp không phải tần sản $(18,1 \mathrm{~mm}$ so với $7,5 \mathrm{~mm} ; \mathrm{p}<0,001) .{ }^{8}$ Tương tự như đại đa số các tài liệu đã được công bố, nghiên cứu của chúng tôi cũng cho thấy tỉ lệ ung thư biểu mô túi mật cao hơn ở những trường hợp polyp kích thước lớn.

Trong nghiên cứu, chúng tôi quan sát thấy tỉ lệ polyp có tính chất u ở những trường hợp có sỏi kèm theo $(15,8 \%)$ cao hơn ở những trường hợp không có sỏi kèm theo. Đồng thời tỉ lệ polyp ung thư ở những trường hợp có sỏi kèm theo (7,0\%) cũng cao hơn ở những trường hợp không có sỏi kèm theo. Tuy nhiên chúng tôi không nhận thây có mối liên quan có ý nghĩa thống kê giữa polyp ung thư và sỏi túi mật do $p>0,05$ (Bảng 3). Một số tác giả coi sỏi mật có thể là yếu tố nguy cơ của polyp túi mật ác tính. Trong khi đó Park và cs (2008) lại cho rằng sỏi mật không phải yễu tố nguy cơ độc lập dựa trên các phân tích đa biến. ${ }^{9}$

\section{KẾT LUÂ̂N}

Nghiên cứu tiến hành trên 95 bệnh nhân được phát hiện có polyp túi mật trên bệnh phẩm phẩu tích túi mật tại bệnh viện Đại học Y Hà Nội, nhận thấy: Trên 50 tuổi, polyp kích thước từ 10 $\mathrm{mm}$ trở lên, chỉ có 01 polyp là các yếu tố có liên quan đến tính chất tân sản hoặc tính chất ác tính của polyp túi mật.

Lời cảm ơn. Nghiên cứu được thực hiện với nguồn kinh phí được tài trợ bởi Bệnh viện Đại học Y Hà Nội. Tác giả Nguyễn Thị Quỳnh được 
tài trợ bởi Tập đoàn Vingroup - Công ty CP và hỗ trợ bởi chương trình học bổng đào tạo thạc sĩ, tiến sĩ trong nước của Quỹ Đổi mới sáng tao Vingroup (VINIF), Viện Nghiên cứu Dữ liệu lớn (VinBigdata), mã số VINIF.2020.ThS.61.

\section{TÀl LIÊU THAM KHẢO}

1. Sarkut P, Kilicturgay $\mathbf{S}$, Ozer A et al. Gallbladder polyps: factors affecting surgical decision. World J Gastroenterol. 2013;19(28): 4526-4530.

2. Salmenkivi $\mathbf{K}$ et al. Cholesterosis of the gall-bladder. A clinical study based on 269 cholecystectomies. Acta chir scand suppl. 1964;105(324):1-93.

3. Yiping $\mathbf{L}$, Talar $\mathbf{T}$ et al. Gallbladder polyps: real or imagined?. The American Surgeon. 2018;84(10): 1670-1674

4. Taskin OC, Basturk O, Reid MD et al. Gallbladder polyps: Correlation of size and clinicopathologic characteristics based on updated definitions. PLoS One. 2020;15(9):e0237979.

5. Roa I, de Aretxabala $X$, Morgan $R$, et al. Pólipos y adenomas de la vesícula biliar: consideraciones clínico-patológicas [Clinicopathological features of gallbladder polyps and adenomas]. Rev Med Chil. 2004;132(6):673-679.

6. Ryol LS, Ook HK, Ho JS. Reasonable cholecystectomy of gallbladder polyp-10 years of experience.Asian journal of surgery. 2019: 332-337.

7. BhattNR, GillisA, SmootheyCOet al. Evidence based management of polyps of the gall bladder: A systematic review of the risk factors of malignancy. Surgeon. 2016;14(5):278-86.

8. Wennmacker SZ, DijkAH, RaessensJHet al. Polyp size of $1 \mathrm{~cm}$ is insufficient to discriminate neoplastic and non-neoplastic gallbladder polyps. Surg Endosc. 2019;33(5):1564-1571.

9. Kyung SJ et al. Management strategies for gallbladder polyps: is it possible to predict malignant gallbladder polyps? Gut Liver. 2008;2(2):88-94.

\title{
MỐI LIÊN QUAN GIỮA NỒNG Độ DOPAMIN HUYÊT TƯO'NG VỚI MộT Số ĐẶC ĐIỂM LÂM SÀNG Ở BÊ̂NH NHÂN TRÂM CẢM CHỦ YẾU
}

\author{
Cao Văn Hiệp*, Đỗ Xuân Tĩnh*, \\ Nguyễn Văn Linh*, Đinh Việt Hùng*, Phạm Thị Thu*
}

\section{TÓM TẮT}

Mục tiêu: Khảo sát mối liên quan giữa nồng độ Dopamin huyết tương với một số đặc điêm lâm sàng ở bệnh nhân trầm cảm chủ yếu. Đối tượng và phương pháp nghiên cứu: Tiến cứu, mô tả cắt ngang trên nhóm bệnh gồm 62 bệnh nhân trầm cảm chủ yếu điều tri nội trú tại Khoa Tẩm thần, bênh viên Quân y 103. Nhóm chứng gồm 31 người khỏe mạnh có sự tương đồng về tuối và giới tính với nhóm bệnh. Kêt quả: Tỷ lệ nam giới ở nhóm nghiên cứu nhiều hơn nữ giới, tuy nhiên sự khác biệt không có ý nghĩa thống kê. Tuồi trung bình của nhóm bệnh và nhóm chứng lần lượt là $38,76 \pm 13,20$ và $39,71 \pm 14,27$; sự khác biệt cũng không có ý nghĩa thống kê với $p>0,05$. Nồng độ Dopamin huyết tương ở nhóm bệnh nhân trầm cảm $(24,96 \pm 12,55 \mathrm{pg} / \mathrm{ml})$ thấp hơn nhóm chứng $(28,72 \pm 11,95 \mathrm{pg} / \mathrm{ml})$, tuy nhiên khác biệt không có ý nghĩa thống kê với $p>0,05$. Nồng độ Dopamin huyết tương ở đối tượng nghiên cứu (nhóm bệnh và nhóm chứng) khác biết không có ý nghĩa thống kê theo giới tính và độ tuổi. Nồng độ Dopamin huyết tương ở nhóm bênh nhân trầm cảm chủ yếu có loạn thần thấp hơn nhóm trầm cảm không có loạn thần, sự khác biệt không có ý nghĩa thống kê $(18,26 \pm 13,32 \mathrm{pg} / \mathrm{ml}$ và $25,68 \pm 12,38 \mathrm{pg} / \mathrm{ml}$, với $\mathrm{p}>0,05)$. Không tồn tại mối liên quan giữa nồng độ Dopamin huyết tương với điểm

*Bệnh viện Quân y 103

Chịu trách nhiệm chính: Cao Văn Hiệp

Email: hatcat275@gmail.com

Ngày nhận bài: 16.9.2021

Ngày phản biên khoa họ: 12.11.2021

Ngày duyệt bài: 24.11.2021
Beck ở nhóm bệnh nhân nghiên cứu. Kết luận: Nồng độ Dopamin huyết tương ở nhóm bệnh nhân trâm cảm chủ yếu ít biến đổi so với nhóm chứng. Nồng độ Dopamin huyết tương ở bệnh nhân trầm cảm chủ yếu không phụ thuộc vào giới tính, tuổi, triệu chứng loạn thần và điểm trắc nghiệm Beck.

Tư khóa: nồng độ Dopamin huyết tương, trâm cảm chủ yếu.

\section{SUMMARY \\ CORRELATION BETWEEN PLASMA CONCENTRATIONS OF DOPAMINE AND SOME CLINICAL PARAMETERS IN PATIENTS WITH MAJOR DEPRESSIVE DISORDER}

Objective: To investigate the correlation between plasma concentrations of Dopamine and some clinical parameters in patients with major depressive disorder. Subjects and Methods: Descriptive cross-sectional study in a patient group of 62 inpatients with major depression treated at the Department of Psychiatry, Military Hospital 103. A control group consisted of 31 healthy participants whose sex and age were similar to the group of patients. Results: The proportion of male subjects was higher than that of female ones, but the difference was not statistically significant. The mean ages in the patients and the controls were $38.76 \pm 13.20$ and $39.71 \pm 14.27$, respectively; the gap was still insignificant, with $p>0.05$. The mean concentrations of Plasma Dopamine in the group of patients was $(24.96 \pm 12.55 \mathrm{pg} / \mathrm{ml})$ lower than the figure for the group of controls $(28.72 \pm 11.95 \mathrm{pg} / \mathrm{ml})$; However, the disparity was not statistically considerable, with $p>0.05$. Dopamine levels in plasma in the subjects (both the patient group and the control 